\title{
Analysis of physical training influence on the technical execution of the dismounts off the uneven bars
}

\author{
Potop V. ${ }^{1 \mathrm{ABCDE}}$, Cretu M. ${ }^{2 \mathrm{ABCDE}}$ \\ ${ }^{1}$ Faculty of Physical Education and Sport, Ecological University of Bucharest, Romania \\ ${ }^{2}$ Faculty of Science, Physical Education and Informatics, University of Pitesti, Romania
}

Authors' Contribution:

A - Study design; B - Data collection; C - Statistical analysis; D - Manuscript Preparation; E - Funds Collection.

\begin{abstract}
Purpose: $\quad$ highlighting of physical training dynamics and its influence on the biomechanical characteristics of the dismounts off uneven bars executed by junior gymnasts aged 12 to 15 years.

Material: $\quad$ a number of 8 gymnasts aged 12 to 15 participated in this research. They performed 12 dismounts off the uneven bars during the Women's Artistic Gymnastics Junior National Championships in the all-around event and apparatus finals. The technical execution of the uneven bars dismounts was assessed by means of Physics ToolKit and Kinovea programs in accordance with the method of movement postural orientation, monitoring the key elements of sports technique. Seven tests of motricity were used in this study: 3 tests for strengthspeed of lower limbs and arms, 3 tests for strength of the abdominal, back and complex muscles and 1 test of specific endurance.

Results: $\quad$ We highlighted the level of specific physical training of junior gymnasts aged 12-15 years; the kinematic and dynamic analysis of the key elements of sports technique in terms of trajectories of body segments, angular speeds and moment of force in the dismounts off uneven bars; also, the dynamics of sports performances achieved in competitions.

Conclusions: regarding the correlation of the physical training indicators with the indicators of the kinematic and dynamic characteristics of the dismounts off uneven bars consistent with the results achieved in competition, we revealed strong connections between indicators at $\mathrm{P}<0.05$ and $\mathrm{P}<0.01$ which confirms the influence of the physical training on the technical execution of the dismounts off uneven bars executed by junior gymnasts.

Keywords: uneven bars, biomechanics, physical training, correlation, performance.
\end{abstract}

\section{Introduction}

Artistic gymnastics has a new development level since the modifications in the Code of Points led to significant changes in the content and structure of the exercise and in the compositional requirements as well [1]. At the same time, gymnastics has made remarkable progress and has demonstrated that it develops in line with the trends of high performance sport $[2,3]$. The knowledge of the biomechanical characteristics and physiological stress of the body in gymnastics requires an accurate assessment of the effort made by athletes [4-6].

An important part of physical training is the increase of athlete's possibilities to use the motor skills both in the training sessions and competitions of that sporting branch. To this end, it is necessary to ensure the specific level of physical training, the interdependent connection of strength and sports technique, the vegetative nervous system activity and the ideal development of the other motor qualities $[7,8]$.

Physical training is one of the most important factors of sports training in the achievement of high performance. The main objectives of physical training are the increase of athlete's physiological potential and the development of the biometric qualities at the highest level [9]. Modern sports training established and finalized, as practical tests for the assessment and evaluation of gymnasts' physical training, the control tests and standards used by coaches

\footnotetext{
(c) Potop V., Cretu M., 2018

doi:10.15561/18189172.2018.0104
}

in numerous variants and combinations of measurements [10].

Physical training represents a process of educating the motor skills required by the correct acquisition of elements, connections and combinations included in the full routines of artistic gymnastics. It is strictly related to the technical, psychological, artistic, tactical and theoretical training [11]. One of the principal goals of physical training is to increase effectiveness, which entails the development of movement execution technicity. In artistic gymnastics practical activity, the physical training has two forms [12]: the general physical training and specific physical training. So, a poor physical training of gymnasts leads to a wrong and faulty technique and thus to failure in competitions. Also, a poor technical training based on good physical training but lacking of proper psychological training leads to modest performances [13].

Nowadays the issue of technical execution correctness in gymnastics is the main criterion for the inclusion of performances on a continuously ascending curve. The complexity of current gymnastics technique requires the use of a new ,technology” able to decipher the internal mechanisms of the movement in order to know and use them for increasing performances. The modern trends come from the field of biomechanics as a scientific branch whose main target is the very discovery of these mechanisms [14-16].

In addition to its specific elements, the exercises on uneven bars (event of women's artistic gymnastics) were 
enriched with new technical procedures not yet mentioned in the specialized literature [17-19]. The technique used in this event includes families of movements, a multitude of elements which provide the essential material appropriate for each gymnast and help to create competition exercises with highly improved movements [20]. The main directions for developing the routines on this apparatus are the following ones [21]: derivation, composition, concentration and loan.

In conformity with the content and construction of exercises on the uneven bars, in the International Code of Points [1] the dismounts are included in the $6^{\text {th }}$ group of elements and are classified in 10 categories where the dismount with swing forward to double salto backward piked has the code 6.305 with difficulty value (DV) C (0.3 point) and the dismount with swing forward to double salto backward tucked with $1 / 1$ turn $\left(360^{\circ}\right)$ in first salto has the code 6.405 with DV - D ( 0.4 point $)$.

The results of the current scientific research on gymnastics biomechanics issues and rotation exercises features are insufficiently studied and known. In this respect, any approach oriented towards the optimization of technical training process is welcome particularly when the biomechanical, anatomical and mechanical matters are transposed in accessible terms [14, 22]. The specialized literature presents the results of several studies on back giant, dismount with double salto and preparatory actions needed to dismount, or elements with release and regrasp of the bar, expressed in kinematic characteristics of the rotations with support on apparatus or without support [23-25]; it also shows the mathematical modeling with the help of PASCAL language [14, 26].

The purpose of the research is to reveal the dynamics of physical training and its influence on the biomechanical characteristics of the dismounts off the uneven bars executed by the gymnasts of 12-15 years old.

\section{Material and methods}

Participants: 8 gymnasts aged 12 to 15 years, members of the Romanian Olympic team of gymnastics since 2014, participated in this research.

Organization of the research: during this research we analyzed 12 dismounts with double salto backward (DST $360^{\circ}, \mathrm{n}=3$ and PDS, $\mathrm{n}=9$ ) executed by 8 junior gymnasts in the all-around event and apparatus finals of the National Championships of Romania, Bucharest 2014.

Statistical analysis: processing the analysis of the research was conducted with statistical-mathematical method by means of "KyPlot" program.

The following research methods have been used to this effect: bibliographic study of specialized literature;

- pedagogical observation;

- video-computerized method, using "Pinnacle Studio" needed to convert the video format recorded in AVI and the synchronization of the sports technique key elements, "Kinovea" - measuring the angular characteristics of the sports technique key elements and "Physics ToolKit" programs for making the biomechanical analysis of the kinematic and dynamic characteristics of double salto backward dismount off uneven bars;

- method of movement postural orientation and evaluation of sports technique key elements with complex coordination of movement structure [27].

The control tests were applied as follows:

A. Strength-speed:

1. Test 1 - standing long jump (2 attempts, $\mathrm{cm}$ );

2. Test 2 - standing high jump (2 attempts, $\mathrm{cm}$ );

3. Test 3 - rope climb with no leg support (seconds).

B. Strength:

4. Test 4 - rib stall hanging leg raise in 30 seconds (no of reps);

5. Test 5 - prone trunk extension in $30 \mathrm{sec}$. (no of reps);

6. Test 6 - handstand on the beam (2 attempts, no of reps);

C. Specific endurance:

7. Test $7-$ handstand hold on the balance beam ( 2 attempts, seconds).

The biomechanical analysis was made by means of Physics ToolKit Version 6.0 and Kinovea programs. We monitored the key elements of sport technique of double salto back dismounts, divided into two parts (fig. 1):

- $\quad$ rotation motion with rotation axis on apparatus, in terms of preparatory movement phase (PM): Sub-phase 1 (SPh1) spring under bar, angle between

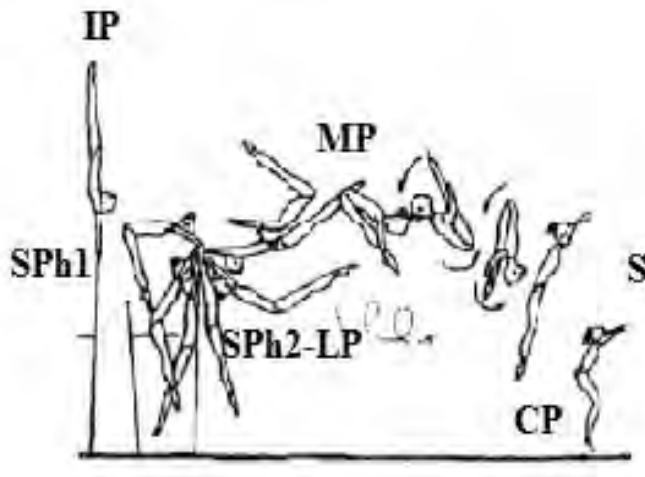

a) Double salto bwd piked (PDS)

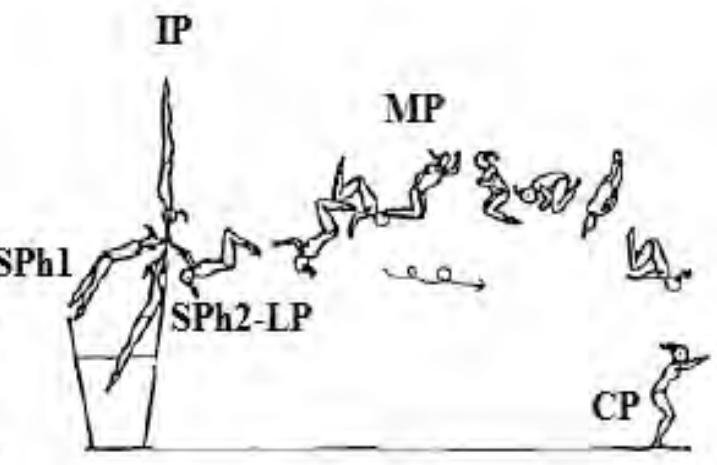

b) Double salto bwd tucked with $360^{\circ}$ turn (DST) $360^{\circ}$

Fig. 1. Key elements of sports technique used in double salto backward dismount off uneven bars 
thigh and torso; Sub-phase 2 (SPh2-LP) body launching posture - moment of release of the bar, $\mathrm{SPh} 2.1$ - thigh-torso angle and $\mathrm{SPh} 2.2$ - arms-torso angle;

- $\quad$ translation and rotation motion with GCG rotation axis regarding the basic movement phase (BM) multiplication of body position (MP) - somersault rotation, thigh-torso angle and final movement phase (FM) - concluding posture (CP) of the body - landing.

\section{Results}

Table 1 shows the dynamics of the physical training indicators in the case of 12 to 15 years old gymnasts in terms of strength-speed, strength and specific endurance development.

The comparative analysis of the physical training level of the gymnasts aged 12 to 15 years old was made by calculating the most usual statistical indicators and the significance of the differences between the means in the initial and final testing of this research (2012 and 2014) using the parametric method $\mathrm{t}$ - Student.

The assessment of strength-speed development level was achieved by using 3 evaluation tests which highlighted the following values:

Test 1 , strength of lower limbs, assessed by standing long jump, shows an average of $186.3 \mathrm{~cm}$ in initial testing and an increase by $8.6 \mathrm{~cm}$ in final testing $(194.9 \mathrm{~cm})$, the coefficient of variation $(\mathrm{Cv} \%)-5.84 \%$ and $4.90 \%$, with significant differences between tests at $\mathrm{p}<0.001(\mathrm{t}=9.97)$;

Test 2, strength of lower limbs, assessed by standing high jump, has an average of $31.8 \mathrm{~cm}$ in initial testing and an increase by $4.6 \mathrm{~cm}$ in final testing $(36.4 \mathrm{~cm}), \mathrm{Cv}$ $-7.67 \%$ and $4.39 \%$, with significant differences between tests at $\mathrm{p}<0.001(\mathrm{t}=12.33)$;

Test 3, strength of upper limbs, assessed by rope climbing with no leg support, indicates an average of 17.3 sec in initial testing and an improvement by $5.1 \mathrm{sec}$ in final testing (12.2 sec), $\mathrm{Cv}-20.38 \%$ and $16.78 \%$, with significant differences between tests at $\mathrm{p}<0.001(\mathrm{t}=6.57)$;

The assessment of strength development level was made by using 3 tests of evaluation which revealed the following values:

Test 4, abdominal strength, assessed by rib stall hanging leg raise in $30 \mathrm{sec}$, shows an average of 19.6 reps in initial testing and an increase by 1.1 reps in final testing (20.7 reps), $\mathrm{Cv}-6.02 \%$ and $3.40 \%$, with significant differences between tests at $\mathrm{p}<0.05(\mathrm{t}=3.33)$;

Test 5, back strength, assessed by trunk extension in $30 \mathrm{sec}$, has an average of 33.9 reps in initial testing and an increase by 2 reps in final testing (35.9 reps), $\mathrm{Cv}-4.30 \%$ and $2.33 \%$, with significant differences between tests at $\mathrm{p}<0.01(\mathrm{t}=5.29)$;

Test 6, complex strength, assessed by power handstand on the balance beam, shows an average of 14.8 reps in initial testing and an increase by 2.3 reps in final testing (17.1 reps), $\mathrm{Cv}-17.28 \%$ and $15.74 \%$, with significant differences between tests at $\mathrm{p}<0.01(\mathrm{t}=3.64)$;

The assessment of specific endurance development level was achieved using only one evaluation test which shows the values as follows:

Test 7 , sense of balance, assessed by holding the handstand position on balance beam, shows an average of $55.6 \mathrm{sec}$ in initial testing and an increase by $10.7 \mathrm{sec}$ in final testing $(66.3 \mathrm{sec}), \mathrm{Cv}-45.44 \%$ and $28.38 \%$, with significant differences between tests at $\mathrm{p}<0.01(\mathrm{t}=4.17)$.

In table 2 are listed the results of the correlation of physical training indicators with the biomechanical characteristics of the dismounts off uneven bars and the performances achieved in competition at the all-around event and apparatus finals during the Romanian National Championships of Women's Artistic Gymnastics, Bucharest 2014.

To demonstrate the influence of physical training indicators on the biomechanical characteristics of the dismounts offuneven bars executed by the gymnasts aged 12 to 15 years and the performances achieved in competition, we made a correlative analysis using "KyPlot” program for statistical calculation (Nonparametric Correlation Spearman's Rank Correlation).

A number of 35 biomechanical indicators involved in the technical execution of the dismounts off uneven bars were selected in this correlative analysis. The data of the kinematic and dynamic characteristics indicators of the dismounts off uneven bars were calculated using Physics Toolkit and Kinovea computerized video programs in conformity with the sports technique analysis method of movement postural orientation [27] as follows:

Table 1. Dynamics of physical training indicators of gymnasts aged $12-15$ years $(n=8)$

\begin{tabular}{|c|c|c|c|c|c|c|c|c|c|c|c|c|c|c|}
\hline \multirow[t]{2}{*}{$\begin{array}{l}\text { Ind. } \\
\text { statist. }\end{array}$} & \multicolumn{6}{|c|}{ Strength - Speed } & $\begin{array}{l}\text { Test } 4 \\
\text { (no of reps) }\end{array}$ & \multicolumn{2}{|c|}{ Strength } & & \multicolumn{2}{|c|}{$\begin{array}{l}\text { Test } 6 \\
\text { (no of reps) }\end{array}$} & \multicolumn{2}{|c|}{$\begin{array}{l}\text { Specific } \\
\text { endurance } \\
\text { Test } 7 \\
\text { (sec) }\end{array}$} \\
\hline & IT & FT & IT & FT & IT & FT & IT & FT & IT & FT & IT & FT & IT & FT \\
\hline $\bar{x}$ & 186.3 & 194.9 & 31.8 & 36.4 & 17.3 & 12.2 & 19.6 & 20.7 & 33.9 & 35.9 & 14.8 & 17.1 & 55.6 & 66.3 \\
\hline SD & 10.87 & 9.55 & 2.43 & 1.59 & 3.53 & 2.04 & 1.18 & 0.70 & 1.46 & 0.83 & 2.55 & 2.69 & 25.27 & 18.80 \\
\hline Cv\% & 5.84 & 4.90 & 7.67 & 4.39 & 20.38 & 16.78 & 6.02 & 3.40 & 4.30 & 2.33 & 17.28 & 15.74 & 45.44 & 28.38 \\
\hline $\mathrm{t}$ & 9.97 & & 12.33 & & 6.57 & & 3.33 & & 5.29 & & 3.64 & & 4.17 & \\
\hline$p$ & $<0.001$ & & $<0.001$ & & $<0.001$ & & $<0.05$ & & $<0.01$ & & $<0.01$ & & $<0.01$ & \\
\hline
\end{tabular}

Note: no of reps - number of repetitions; IT - initial testing; FT - final testing 
Table 2. Correlation of physical training indicators with the biomechanical characteristics of the dismounts off the uneven bars and the performances achieved in competition $(n=12)$

\begin{tabular}{|c|c|c|c|c|c|c|c|c|c|c|}
\hline \multirow[b]{2}{*}{ No. } & \multicolumn{3}{|l|}{$\mathbf{r}$} & \multicolumn{3}{|c|}{ Strength - Speed } & \multicolumn{3}{|c|}{ Strength } & \multirow{2}{*}{$\begin{array}{l}\text { Specific } \\
\text { Endur. } \\
\text { Test } 7 \\
\text { (sec) }\end{array}$} \\
\hline & \multicolumn{3}{|c|}{ Biomechanical indicators } & $\begin{array}{l}\text { Test } 1 \\
(\mathrm{~cm})\end{array}$ & $\begin{array}{l}\text { Test } 2 \\
(\mathrm{~cm})\end{array}$ & $\begin{array}{l}\text { Test } 3 \\
\text { (sec) }\end{array}$ & $\begin{array}{l}\text { Test } 4 \\
\text { (reps } \\
\text { no) }\end{array}$ & $\begin{array}{l}\text { Test } 5 \\
\text { (reps } \\
\text { no) }\end{array}$ & $\begin{array}{l}\text { Test } 6 \\
\text { (reps } \\
\text { no) }\end{array}$ & \\
\hline 1 & \multirow{4}{*}{$\begin{array}{l}\text { Phase of } \\
\text { rotation with } \\
\text { support }\end{array}$} & \multicolumn{2}{|c|}{$\mathrm{IR},\left(\mathrm{kg} \cdot \mathrm{m}^{2}\right)$} & .383 & -.126 & .418 & -.315 & -.487 & .964 & .237 \\
\hline 2 & & \multirow{3}{*}{$\mathrm{RM},(\mathrm{m})$} & toes & .074 & .048 & .384 & -.238 & -.227 & .611 & .111 \\
\hline 3 & & & GCG & -.011 & .111 & .419 & -.324 & -.212 & .611 & .168 \\
\hline 4 & & & should & .021 & .126 & .239 & -.145 & .171 & .493 & .136 \\
\hline 5 & \multirow{4}{*}{$\begin{array}{l}\text { Phase of } \\
\text { rotation } \\
\text { without } \\
\text { support }\end{array}$} & \multicolumn{2}{|c|}{$\mathrm{IR},\left(\mathrm{kg} \cdot \mathrm{m}^{2}\right)$} & .383 & -.127 & .418 & -.315 & -.488 & .964 & .237 \\
\hline 6 & & \multirow{3}{*}{$\begin{array}{l}\mathrm{RM}, \\
(\mathrm{m})\end{array}$} & toes & .359 & .436 & .056 & -.540 & -.033 & .436 & -.050 \\
\hline 7 & & & should & .228 & .115 & .313 & -.442 & -.305 & .501 & .063 \\
\hline 8 & & & arms & -.164 & -.063 & .344 & -.287 & -.341 & .088 & .152 \\
\hline 9 & \multirow{5}{*}{$\begin{array}{l}\text { KE } \\
\text { dismounts } \\
\text { sport } \\
\text { technique, } \\
\text { (degrees) }\end{array}$} & \multicolumn{2}{|l|}{ SPh1 } & .624 & .481 & -.183 & -.396 & .157 & .698 & -.007 \\
\hline 10 & & \multirow{2}{*}{ SPh2 } & LP1 & -.487 & -.098 & .046 & .771 & -.045 & -.401 & -.716 \\
\hline 11 & & & LP2 & .164 & .193 & -.108 & -.173 & .059 & -.116 & -.116 \\
\hline 12 & & \multicolumn{2}{|l|}{$\mathrm{MP}$} & -.265 & -.022 & .131 & -.119 & .286 & -.133 & .333 \\
\hline 13 & & \multicolumn{2}{|l|}{$\mathrm{CP}$} & .530 & -.256 & .102 & -.383 & -.488 & .215 & .122 \\
\hline 14 & \multirow[t]{2}{*}{ SPh1 } & \multirow[t]{2}{*}{$\begin{array}{l}\text { toes, } \\
\text { (m) }\end{array}$} & $x$ & -.369 & -.118 & -.229 & .533 & .029 & -.482 & -.189 \\
\hline 15 & & & $y$ & .539 & .318 & .025 & -.413 & .059 & .768 & .096 \\
\hline 16 & \multirow{2}{*}{ SPh2-LP } & \multirow{2}{*}{$\begin{array}{l}\text { toes, } \\
\text { (m) }\end{array}$} & $x$ & -.665 & .322 & -.208 & .399 & .059 & -.154 & .018 \\
\hline 17 & & & $y$ & .496 & .015 & .187 & -.569 & .261 & -.032 & -.125 \\
\hline 18 & \multirow{2}{*}{ MP } & \multirow{2}{*}{$\begin{array}{l}\text { GCG, } \\
(\mathrm{m})\end{array}$} & $x$ & -.559 & .340 & -.137 & .298 & -.019 & -.118 & -.118 \\
\hline 19 & & & y & .898 & .048 & -.074 & -.652 & .041 & .204 & -.014 \\
\hline 20 & \multirow{2}{*}{$\mathrm{CP}$} & \multirow{2}{*}{$\begin{array}{l}\text { should, } \\
\text { (m) }\end{array}$} & $x$ & -.391 & .425 & -.271 & .324 & .022 & .068 & -.118 \\
\hline 21 & & & $y$ & .528 & -.211 & .106 & -.484 & -.503 & .236 & .207 \\
\hline 22 & SPh1 & toes, (rad & & -.179 & -.395 & .095 & .175 & .063 & -.489 & .039 \\
\hline 23 & SPh2-LP & toes, (rad & & .000 & .303 & -.634 & .379 & .283 & -.143 & -.071 \\
\hline 24 & & toes, (rad & & .158 & .669 & -.573 & -.402 & .291 & -.076 & .211 \\
\hline 25 & IVIP & should, (r & $\mathrm{ad} / \mathrm{s})$ & .127 & .373 & -.521 & -.264 & .246 & -.414 & .136 \\
\hline 26 & $C D$ & toes, (rad & & -.602 & .392 & -.433 & .216 & .216 & -.704 & -.046 \\
\hline 27 & Cr & should, ( $r$ & $\mathrm{ad} / \mathrm{s})$ & .317 & .244 & .204 & -.432 & -.332 & .793 & .164 \\
\hline 28 & SPh1 & toes, $(\mathrm{N})$ & & .222 & -.052 & -.067 & .194 & .279 & -.139 & -.375 \\
\hline 29 & SPh2-LP & toes, $(\mathrm{N})$ & & .518 & .081 & -.059 & .022 & -.101 & .632 & -.154 \\
\hline 30 & $\mathrm{MP}$ & GCG, (N) & & -.275 & .662 & -.739 & .294 & .219 & -.336 & -.186 \\
\hline 31 & $\mathrm{CP}$ & GCG, (N) & & .275 & -.395 & .634 & -.194 & -.540 & .750 & .100 \\
\hline 32 & & & toes & -.042 & .717 & -.662 & -.268 & .298 & -.071 & .343 \\
\hline 33 & IVIP & & should & .359 & .366 & -.408 & -.469 & .209 & .036 & .329 \\
\hline 34 & $C D$ & RF (I) & toes & .592 & -.251 & .190 & -.458 & -.123 & .200 & .057 \\
\hline 35 & Cr & קט & should & .539 & .225 & -.095 & -.317 & .357 & .354 & -.054 \\
\hline 36 & Results comp & tition (poir & & .413 & -.304 & .183 & -.285 & .154 & .426 & .440 \\
\hline
\end{tabular}

Note: fig. 1; KE - key elements, IR - inertia of rotation, IR in the phase of rotation without support was calculated $1 / 2 \mathrm{~kg} \cdot 1 / 2 \mathrm{~m}^{2}, \mathrm{RM}$ - radius of movement, GCG -general center of gravity, Nonparametric Correlation Spearman Rank Correlation

1) Biomechanical indicators required by the analysis: inertia of rotation $\left(\mathrm{IR}, \mathrm{kg} \cdot \mathrm{m}^{2}\right)$ during the rotation phase with and without support on apparatus, radius of movement (RM, m) of body segments during rotation phase with or without support on apparatus.

2) Angular characteristics of key elements of sports technique (fig. 1): rotation motion with rotation axis on apparatus, in terms of preparatory movement phase (PM): Sub-phase 1 (SPh1) spring under bar, angle between thigh and torso; Sub-phase 2 (SPh2-LP) body launching posture - moment of release of the bar, $\mathrm{SPh} 2.1$ - thigh-torso angle and 
SPh2.2 - arms-torso angle; translation and rotation motion with GCG rotation axis regarding the basic movement phase (BM) - multiplication of body position (MP) - somersault rotation, thigh-torso angle and final movement phase (FM) - concluding posture (CP) of the body - landing.

3) Spatial characteristics of the trajectory of body segments movement: PM: SPh1 - toes (m), SPh2LP - toes (m), BM: MP - GCG (m) and FM - CP - shoulders (m).

4) Characteristics of angular speed (omega): PM: SPh1 - toes ( $\mathrm{rad} / \mathrm{s}), \mathrm{SPh} 2-\mathrm{LP}$ - toes $(\mathrm{rad} / \mathrm{s}), \mathrm{BM}$ : MP - GCG-toes ( $\mathrm{rad} / \mathrm{s})$ and GCG-shoulders ( $\mathrm{rad} / \mathrm{s})$ and FM - CP - GCG - toes ( $\mathrm{rad} / \mathrm{s})$ and GCG shoulders $(\mathrm{rad} / \mathrm{s})$.

5) Characteristics of the resultant force (F): PM: SPh1 - toes $(\mathrm{N})$, SPh2- LP - toes $(\mathrm{N}), \mathrm{BM}$ : MP - GCG (N) and FM - CP - GCG (N).

6) Characteristics of the resultant energy (RE): PM: SPh1 - toes (J), SPh2- LP - toes (J), BM: MP GCG-toes (J) and GCG-shoulders (J) and FM - CP - GCG - toes (J) and GCG - shoulders (J).

7) Results achieved in all-around event and apparatus finals on uneven bars during the Romanian National Championships of Women's Artistic Gymnastics, Bucharest, 2014.

\section{Discussions}

The results of the correlative analysis of the influence of physical training indicators upon the biomechanical characteristics of the dismounts off uneven bars reveal the following matters (table 2):

- strong connections at $\mathrm{p}<0.01, \mathrm{r}=.964$ between the inertia of rotation (IR, $\mathrm{kg} \cdot \mathrm{m}^{2}$ ) during rotation phase on apparatus with support and without support as well and test 6 (power handstand, no of reps);

- strong connections at $\mathrm{p}<0.05, \mathrm{r}=.611$ between the radius of movement (RM, m), toes and GCG and the test 6 in the phase of rotation with support, considering that the IR in both phases of rotational movement (with and without support) - test 6 (complex strength) can influence the technical execution of the dismounts.

In terms of indicators of the angular characteristics of sports technique key elements of the dismounts off the uneven bars, we notice strong connections at $\mathrm{p}<0.05$ in the phase of preparatory movement (PM) between the hip - trunk angle in SPh1 (moment of toes passage over the low bar) and test 1 (standing long jump), $r=.624$ and test 6 (power handstand on balance beam), $\mathrm{r}=.698$; in SPh2-LP the launching posture (moment before releasing the upper bar), the hip - trunk angle and test 4 ( rib stall hanging leg raise in $30 \mathrm{sec}$ ), $\mathrm{r}=.771$ and test 7 (handstand position hold on balance beam), $\mathrm{r}=.716$; in the basic movement phase (BM), the multiplication of the body posture (MP) has poor connections with tests 1,5 and 7 while in the phase of final movement (FM), concluding posture (CP) landing it has moderate connections with test 1 (strength of lower limbs), r=.530 and test 4 (abdominal strength), $\mathrm{r}=.488$ - both tests could influence the technical execution of the landing.

Regarding the indicators of the spatial characteristics of the trajectory of body segments movement during the execution of the dismounts off uneven bars in the preparatory movement phase (MP), SPh1 - toes (X, m), there are moderate connections with test 4 (abdominal strength) and strong connections at $\mathrm{p}<0.05$ - toes (Y, m) with test 6 (complex strength), $r=.768$; they influence the technical execution of toes passing over the low bar. There are strong connections at $\mathrm{p}<0.05$ in $\mathrm{SPh} 2-\mathrm{LP}$, between toes $(\mathrm{X}, \mathrm{m})$ and test 1 (explosive strength of lower limbs), $\mathrm{r}=.665$, which influence the most efficient release of the bar; in the basic movement phase (BM) there are strong connections at $\mathrm{p}<0.01$ between the multiplication of posture at the moment of the highest position of GCG and test $1, r=898$ and test 4 at $p<0.05, r=.652$. We believe that both tests have an influence upon the technical execution of the flight phase of the dismounts. In the final movement phase (FM), concluding posture (CP), there are moderate connections between shoulders and tests 1 and 5 (strength of lower limbs and strength of the back) which influence the stuck landing.

As for the indicators of the angular speed during the execution of the dismounts off the uneven bars in the phase of preparatory movement (PM), SPh1 - toes angular speed ( $\mathrm{rad} / \mathrm{s})$, we notice moderate connections with test 6 (complex strength) while in $\mathrm{SPh} 2-\mathrm{LP}$, toes $(\mathrm{rad} / \mathrm{s})$ there are strong connections at $\mathrm{p}<0.05$ with test 3 (arms strength-speed), $\mathrm{r}=.634$; in the basic movement phase (BM), MP - the angular speed of toes around the GCG has strong connections at $\mathrm{p}<0.05$ with test 2 (vertically explosive strength of the lower limbs), $r=.669$ while the shoulders $(\mathrm{rad} / \mathrm{s})$-moderate connections. In the final movement phase (FM), toes ( $\mathrm{rad} / \mathrm{s})$ there are strong connections at $\mathrm{p}<0.05$ with test 1 (explosive strength of lower limbs), $\mathrm{r}=.602$ and test 6 (complex strength), $\mathrm{r}=.704$. It is confirmed that all tests that have strong connections or even moderate ones influence the correct execution of positions in the key elements of sports technique used in the dismounts off uneven bars.

In terms of indicators of the resultant force of body segments during the execution of the dismounts off uneven bars in PM, SPh1 (toes, N) we observe weak connections with tests 5 and 7 (strength of back and sense of balance); in SPh2 - LP there are strong connections at $\mathrm{p}<0.05$ between $\mathrm{F}$, toes $(\mathrm{N})$ and test 6 (complex strength), $\mathrm{r}=.632$ and moderate connections with test 1 (explosive strength of lower limbs); in BM, MP - there are strong connections at $\mathrm{p}<0.05$ between $\mathrm{F}$ of GCG movement at the moment of flight maximum moment and test 2, $\mathrm{r}=.662$ and test $3, \mathrm{r}=.739$; in FM phase, CP shows strong connections at $\mathrm{p}<0.05$ between GCG movement and test $3, r=.634$ and test $6, r=.750$. All these strong connections during the phasic structure confirm the influence of physical training level on the technical execution of the dismounts off uneven bars.

Concerning the resultant energy (RE, J), it was analyzed in the basic and final phase of the dismounts, 
highlighting - in the multiplication of body posture (MP) strong connections at $\mathrm{p}<0.05$ between the resultant energy of toes $(\mathrm{J})$ around GCG rotation with the test $2, \mathrm{r}=.717$ and test $3, r=.662$ while the resultant energy of shoulders (J) has moderate connections with tests 3 and 4 ; in final phase (FM), concluding posture (CP) it has strong connections at $p<0.05$ between the toes resultant energy $(\mathrm{J})$ and test $1, r=.592$ while for shoulders $(J)$ - there are moderate connections with test 1 . Given the strong connections of test 1 with the resultant energy accumulated in the SPh1 and $\mathrm{SPh} 2-\mathrm{LP}$, toes preparatory movement phase, we are able to confirm its influence on the technical execution in the flight phase (flight - rotation movement without support), multiplication of body posture (MP) and final phase - concluding posture (CP) - landing.

The results obtained in uneven bars events highlight moderate connections with test 1 (explosive strength of lower limbs) and test 7 (sense of balance) and poor connections with the other tests. These connections confirm the importance of the dismount within the content of the exercise on uneven bars; the level of development of muscle strength and coordinative capacity - balance can influence the final score in competition.

\section{Conclusions}

The comparative analysis of the 12-15 years old gymnasts' physical training reveals the dynamics of the development of lower limbs explosive strength, upper limbs strength-speed, abdominal strength, back strength and, last but not least, the sense of balance - component of the coordinative capacity.
The influence of physical training indicators on the kinematic and dynamic characteristics of the dismounts off the uneven bars executed by the gymnasts aged 12 to 15 years highlights strong connections at $\mathrm{P}<0.01$ and $\mathrm{P}<0.05$ and moderate or even poor connections between the analyzed indicators. This fact confirms the importance of the correlative connection between the physical training and the technical execution of these dismounts.

\section{Acknowledgements}

This case study is an advanced stage of the pedagogical experiment of the post-doctoral thesis; it is included in the research plan of National University of Physical Education and Sport of Ukraine, with the subject matters: 2.11 (Dynamic static stability as a basis for technical training of those involved in sports gymnastics views), 2.32 (Technical training of qualified athlete based on competitive exercises technique rationalization) and in the plan of research for 2016-2017 of the Faculty of Physical Education and Sport, Ecological University of Bucharest. We express our gratitude to the Romanian Gymnastics Federation and especially to Missis Anca Grigoraș Mihailescu - federal coach and to the coaches of the Olympic Team of Izvorani who helped us to conduct this research.

\section{Conflict of interests}

The authors declare that there is no conflict of interests.

\section{References}

1. Code of Points 2017-2020. Women's Artistic Gymnastics, Part III, Apparatus, Section 11 - Uneven Bars; Part IV Tables of elements. International Gymnastics Federation (FIG); 2017.

2. Arkaev LJ, Suchilin NG. How to create champions. Theory and technology of training. Top-class gymnasts. Moscow: Physical Culture and Sport; 2004. (in Russian)

3. Potop V. Bases of Macro-methods for Sports Exercises Learning (material from Women's Artistic Gymnastics). Kiev: Education Literature Center; 2015. (in Russian)

4. Cretu M. Improvement of the technique of back giant and back somersault dismount off uneven bars. Publishing House of Pitești University; 2004. (in Romanian)

5. Prassas S, Kwon YH, Sands W. Biomechanics of artistic gymnastics. Journal of Sport Biomechanics, 2006; 5: 261292.

6. Timnea OC. Physiology of physical effort. Bucharest: "Bren" Publishing house; 2010. (in Romanian)

7. Dragnea A, Teodorescu-Mate S. Theory of Sport. FEST Publishing House; 2002. (in Romanian)

8. Triboi V, Păcuraru A. Theory and methods of sports training. Iași: PIM Publishing House; 2013. (in Romanian)

9. Bompa TO. Periodization: Theory and Methodology of Training. Bucharest: Ex Ponto Publishing House; 2002. (in Romanian)

10.Simion Gheorghe, Mihăilă Ion, Stănculescu George. Sports Training. Systemic Concept. Constanta: Ovidius University Press; 2011. (in Romanian)

11.Platonov VN. Training System of Athletes in Olympic Sport.
General Theory and its Practical Application. Kiev: Olympic Literature; 2015. (in Russian)

12.Vieru N. Handbook of sports gymnastics. Bucharest: "Driada" Publishing House; 1997. (in Romanian)

13.Grigore V. Artistic gymnastics - theoretical bases of sports training. Bucharest: Semne; 2001. (in Romanian)

14.Crețu M, Simăn I, Bărbuceanu M. Biomechanics of back giant on uneven bars. Publishing House of Pitești University; 2004. (in Romanian)

15.Timnea OC, Baican MS. Anatomy and biomechanics. Bucharest: "Discobolul" Publishing House; 2017. (in Romanian)

16.Ulareanu MV. Metode si tehnici de tonifiere a musculaturii [Methods and techniques of toning muscles]. Bucharest: Printech Publishing hause; 2015. (In Romanian)

17.Gaverdovskij JK. Theory and Methods of Artistic Gymnastics: Moscow: Soviet sport; 2014. (in Russian)

18.Potop V. Assessment of Physical and Technical Training Level in Basic Specialization Stage in Women's Artistic Gymnastics. Journal of Physical Education and Sport, 2013,13(1): 114-119. doi:10.7752/jpes.2013.01019

19.Ulareanu MV, Nicu V. Antrenamentul de baza in haltere de performanta [Basic training in weightlifting performance]. Bucharest: Printech Publishing hause; 2014. (In Romanian)

20.Dobrescu T, Bibire M. Uneven bars - concepts and modern methodologies. Iasi: PIM Publishing House; 2008. (in Romanian)

21.Grosu EF. Uneven bars of women's artistic gymnastics. Gymnastics. Cluj-Napoca: GMI Publishing House; 2004. (in Romanian) 
22.Hiley MJ, Yeadon MR. Optimization of Backward Giant Circle Technique on the Asymmetric Bars. Journal of Applied Biomechanics, 2007; 23:300-308.

23.Potop V, Grigore V, Timnea, OC, Ulareanu MV. Biomechanical characteristics of transfer in the rotation movements on uneven bars. Applied Mechanics and Materials, 2014;1: 650-660.

24.Potop V, Timnea OC, Mihaiu C, Manole C. Biomechanical characteristics of back double salto dismount off the uneven bars. Journal of Physical Education and Sport, 2014; 14(2): 248-253.
25.Potop V, Timnea O, Stănescu M. Comparative analysis of the biomechanical characteristics of sports technique used in dismounts and performances achieved by junior gymnasts in uneven bars events. Conference proceedings "Informatics, Geoinformatics and Remote Sensing”. 2017;21:191-198. https://doi.org/10.5593/SGEM2017/21/S07.025

26.Smolevskij VM, Gaverdovskij JK. Artistic gymnastics. Kiev: Olympic Literature; 1999. (in Romanian)

27.Boloban VN. Regulation of athlete's body posture. Kiev: Olympic Literature; 2013. (in Russian)

\section{Information about the authors:}

Potop Vladimir (Corresponding author); http://orcid.org/0000-0001-8571-2469; vladimir_potop@yahoo.com; Faculty of Physical Education and Sport, Ecological University of Bucharest Bulevardul General Vasile Milea 1G, București 061341, Romania.

Cretu Marian; http://orcid.org/0000-0003-1934-0534; marian.cretu@efsupit.ro; Faculty of Science, Physical Education and Informatics; University of Pitesti; Str. Targul din Vale, nr.1, 110040 Pitesti, Arges, Romania.

Cite this article as: Potop V, Cretu M. Analysis of physical training influence on the technical execution of the dismounts off the uneven bars. Pedagogics, psychology, medical-biological problems of physical training and sports, 2018;22(1):28-34. doi:10.15561/18189172.2018.0104

The electronic version of this article is the complete one and can be found online at: http://www.sportpedagogy.org.ua/index.php/PPS/issue/archive

This is an Open Access article distributed under the terms of the Creative Commons Attribution License, which permits unrestricted use, distribution, and reproduction in any medium, provided the original work is properly cited (http://creativecommons.org/licenses/by/4.0/deed.en).

Received: 30.10 .2017

Accepted: 25.11.2017; Published: 26.02.2018 